\title{
Soil Water Characteristic Curve of an Unsaturated Soil under Low Matric Suction Ranges and Different Stress Conditions
}

\author{
Paul Habasimbi ${ }^{*}$, Tomoyoshi Nishimura² \\ ${ }^{1}$ Graduate School of Engineering, Ashikaga University, Omae Ashikaga Tochigi, Japan \\ ${ }^{2}$ Department of Civil Engineering, Ashikaga University, Omae Ashikaga Tochigi, Japan \\ Email: ^habapaul@yahoo.co.uk, tomo@ashitec.ac.jp
}

How to cite this paper: Habasimbi, P. and Nishimura, T. (2019) Soil Water Characteristic Curve of an Unsaturated Soil under Low Matric Suction Ranges and Different Stress Conditions. International Journal of Geosciences, 10, 39-56.

https://doi.org/10.4236/ijg.2019.101004

Received: December 27, 2018

Accepted: January 25, 2019

Published: January 28, 2019

Copyright $\odot 2019$ by author(s) and Scientific Research Publishing Inc. This work is licensed under the Creative Commons Attribution International License (CC BY 4.0).

http://creativecommons.org/licenses/by/4.0/

\begin{abstract}
Accurate evaluation of unsaturated soil properties is critical for the design of geotechnical and geo-environmental structures such as road pavements, foundations, and earth dams. Water retention activity in soils which is used to predict the stability or seepage problems in the ground is one of the key features in unsaturated soil mechanics. Thus, many experimental works have reported on the unsaturated soil properties, and the soil-water characteristic curve (SWCC) test has contributed significantly to the interpretation of matric suction. Since traditional instruments cannot apply stress in SWCC tests, some researchers have developed suction controlled triaxial apparatus, by which SWCC tests are performed under different stress states. Determination of SWCCs under stress conditions similar to those in the field is key for interpretation of the hydro-mechanical behavior of unsaturated soils. This study conducted SWCC tests of unsaturated silt soil in low matric suction ranges under both drying and wetting conditions. The SWCCs were measured under one-dimensional and isotropic confining stresses ranging from 50 to $450 \mathrm{kPa}$. The micro porous membrane method was used instead of high air entry ceramic disk for controlling relatively low matric suction. The range of matric suction controlled was from 0 to $20 \mathrm{kPa}$. The study revealed that the measured SWCC in low matric suction ranges seems to be affected by the influence of stress conditions. Isotropic confining stress caused the void structure of the specimen to become dense and consequently, soil moisture flow movement also decreased. The water retention activity was obviously high, and the point regard to air entry value was larger. The study further suggests that the current methods adopted for estimating unsaturated soil properties require further development to take into account the effect of different stress conditions.
\end{abstract}




\section{Keywords}

Soil Water Characteristic Curve, Suction, Unsaturated Soil, Membrane Technique

\section{Introduction}

Soils with negative pore pressures are usually referred to as unsaturated soils. The voids of these soils are normally filled with both water and air. The Soil Water Characteristic Curve (SWCC), which represents the capacity of the soil to store and release water when matric suction is applied, is defined as the relationship between the matric suction and the degree of saturation or gravimetric water content for unsaturated soils. In this regard, the SWCC has widely been identified as the key soil information required for the analysis of seepage, stability and volume change problems involving unsaturated soils. Thus far, SWCC tests are conducted to explain matric suction (i.e. the difference between pore air pressure and pore water pressure) effort on hydro-mechanical properties for unsaturated soils. Conventionally, SWCCs are determined in the laboratory using a pressure plate apparatus in which vertical or confining stress cannot be applied [1] [2]. Since traditional instruments cannot apply stress in SWCC tests, several researchers have developed suction controlled triaxial apparatus, by which SWCC tests are performed under different stress states [3] [4]. A number of models/empirical functions have been proposed over the years to describe the SWCC as direct measurements are time-consuming and expensive, both in the field and laboratory. These models (e.g., Gardner 1958, Brooks and Corey 1964, van Genuchten 1980, Williams et al. 1983, and Fredlund and Xing 1994) which are in the form of mathematical equations are usually fitted to experimental data from the laboratory. To the authors' knowledge, these empirical expressions commonly used to describe the SWCCs rarely adequately capture the effect of different stress conditions on SWCCs. Due to the depositional history in the field, a soil normally experiences some kind of stress [2] [5] [6]. In addition, the shape of the SWCC is dependent on many factors which include soil mineralogy and grain size distribution which is also related to the pore size distribution of the soil. Stress state, compaction effort, and soil structure are other parameters that can have an influence on the shape of the SWCC [7] [8]. Therefore, it is important to investigate experimentally the influence of different magnitudes of stress on unsaturated soil under low matric suction ranges. Besides, there is quite limited information in the literature with experimental data on SWCCs measured under low matric suction ranges and different stress conditions. The purpose of this study is to present experimental test results of SWCCs determined in low matric suction range and under different stress conditions for an unsaturated silt soil. The specific ranges of matric suction considered in this study are from 0 to $20 \mathrm{kPa}$ which is also related to most disasters induced due to rainfall in the geotechnical engineering practice. 
In order to approach the target of this research, SWCCs of a silt soil measured under one-dimensional and isotropic stress conditions were conducted. The SWCCs were actually measured with different stress magnitudes ranging from 50 to $450 \mathrm{kPa}$ allowing assessment of the influence of different stress conditions. The micro porous membrane [9] [10] [11] [12] [13] was used instead of high air entry ceramic disk for controlling relatively low matric suction which is one of the latest testing methods in SWCC tests. The equilibrium time required for SWCC measurements using the micro porous membrane is much shorter than that of the high air entry ceramic disks. To this extent, the micro porous membrane was significantly useful in shortening the testing time for the experiments. The range of matric suction controlled in this test was from zero to twenty in $\mathrm{kPa}$. The results of this research perhaps could be useful in providing relevant data for understanding the coupled hydro-mechanical behavior of unsaturated silt soil in the geotechnical engineering practice.

\section{Experimental Study}

\subsection{Soil Material and Specimens}

The soil material used for the experimental work in this study is Japanese standard silt commonly known as DL Clay. The soil material is a commercial product that is used widely in laboratory tests by many Japanese learning institutions and practitioners for research purposes. It was chosen for this study because it has a low degree of saturation and is non-plastic. Test specimens were prepared using a steel mold and compacted using a static hydraulic compaction apparatus as shown in Figure 1. According to the Japanese test methods for compaction, JIS (2009a) standard A1210 [14], the results of the standard Proctor compaction test indicated a maximum dry density of $1.535 \mathrm{~g} / \mathrm{cm}^{3}$ at an optimum water content of $17 \%$. Figure 2 shows the relationship between water content and dry

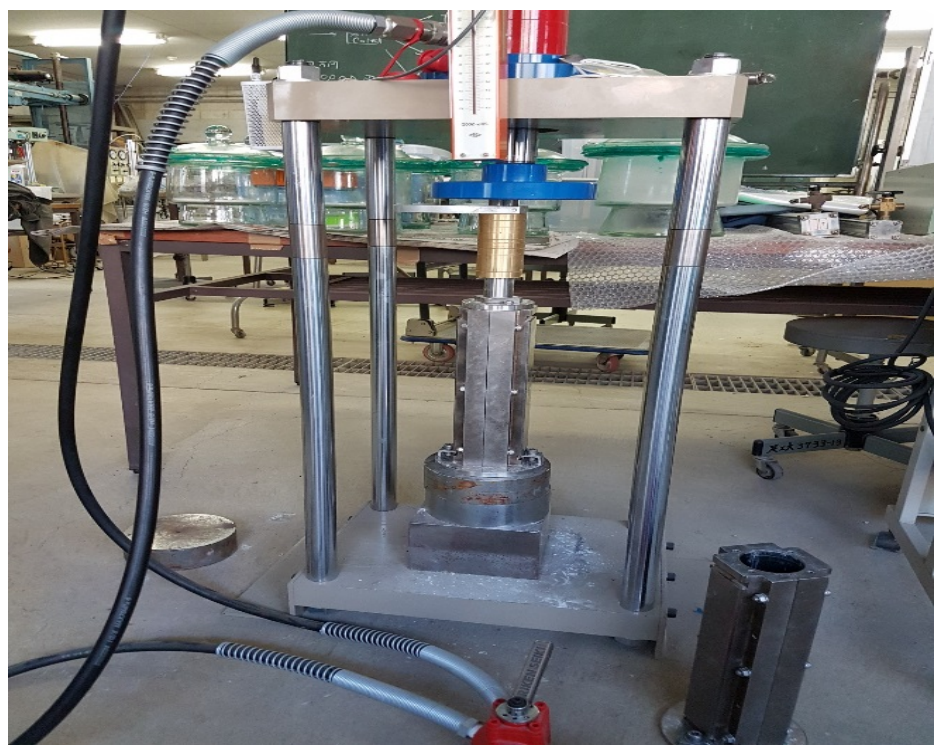

Figure 1. Setup of static compaction of silt using a steel mold. 


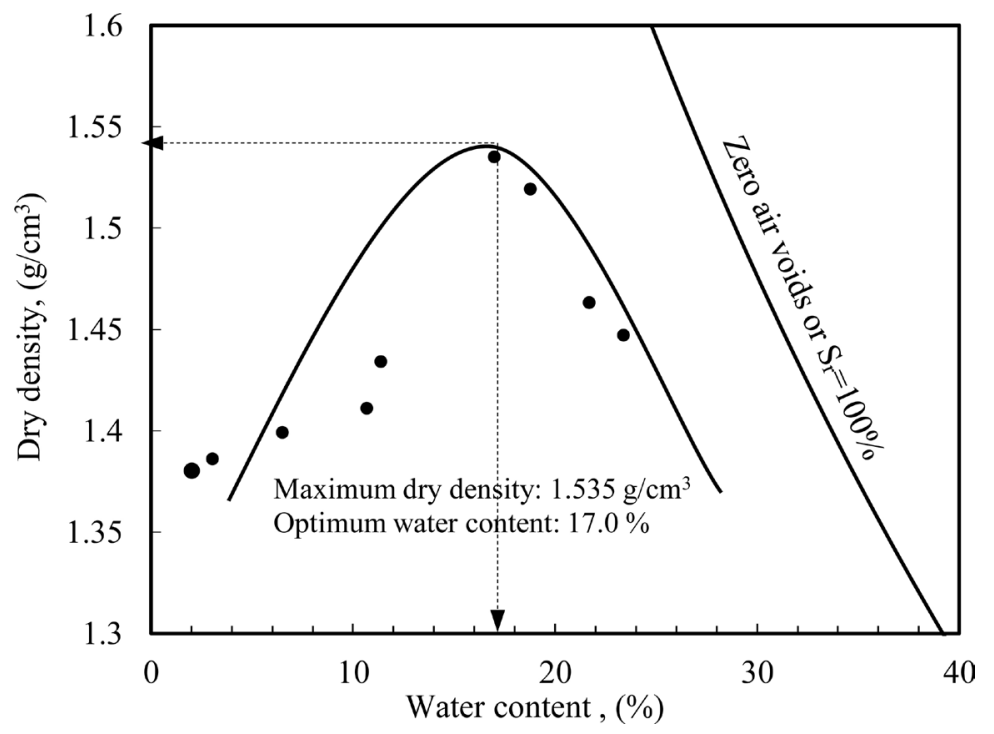

Figure 2. Compaction curve for silt soil.

Table 1. Properties of silt soil.

\begin{tabular}{cc}
\hline Property & Result \\
\hline Specific gravity & 2.65 \\
Percentage of sand fraction\% & 1.00 \\
Percentage of silt fraction\% & 87.00 \\
Percentage of clay fraction\% & 12.00 \\
Fine component\% & 99.00 \\
Mean grain diameter of silt $\mathrm{D}_{50} \mathrm{~mm}$ & 0.02 \\
Void ratio & 0.726 \\
Liquid limit $\%$ & 24.70 \\
Plastic limit $\%$ & 22.80 \\
Plasticity index & 1.90 \\
Unified Soil Classification System & ML \\
Maximum dry density g/cm & \\
Optimum water content $\%$ & 1.53 \\
\hline
\end{tabular}

Note. ML stands for low plastic silt in accordance with the Unified Soil Classification System.

density as compaction curve of the soil. The soil material has a relatively uniform grain size distribution and it was classified as low plastic silt according to the Unified Soil Classification System. Its index properties such as liquid limit, plastic limit, plasticity limit, soil particle density, void ratio, the mean grain diameter of sand $\left(\mathrm{D}_{50}\right)$ and silt are summarized in Table 1. Statically compacted specimens of diameter $50 \mathrm{~mm}$ and height $100 \mathrm{~mm}$ were prepared for SWCC tests in isotropic compression conditions. Additional specimens of diameter 60 $\mathrm{mm}$ and height $65 \mathrm{~mm}$ were prepared for SWCC tests in one-dimensional compression conditions. The specimen size for one-dimensional compression test was basically governed by oedometer tests for saturated soils. 


\subsection{Apparatus}

The research presented in this paper conducted SWCC tests experimentally using a modified triaxial apparatus as shown in the setup arrangement in Figure 3. The pedestal of the apparatus was modified and fixed with a microporous membrane which had an air entry value of $250 \mathrm{kPa}$. The membrane filter was saturated separately and immediately fixed by a stainless cover. The apparatus mainly comprised the triaxial cell, pedestal, a double glass burette connected to a differential pressure transducer, an inner and outer cell, and supply systems for cell pressure, pore-water pressure and pore-air pressure. The salient feature of this modified triaxial apparatus is that it allowed for the independent control/measurement of the cell pressure, pore-water pressure, and pore-air pressure. A gap sensor installed into the inner cell was used to measure the volume change of the soil specimen. The gap sensor essentially measures voltage changes which can also be converted to volume changes of the specimen. A differential pressure transducer which was attached to the lower portion of the double glass burette was also calibrated to directly give a relationship between the voltage and the volume of water in the glass burettes. The calibration curve is shown in Figure 4 .

\section{Test Methodology}

\subsection{Soil Water Characteristic Curve Tests}

The axis translation technique which relies mostly on the unique properties of the high air entry ceramic disks has been widely used for the measurement of the SWCC in geotechnical engineering practice. However, high air entry ceramic disks commonly used in this technique have suffered a lot of disadvantages such as the difficulty of saturating the disk, relatively slow response of measuring suction and consuming too much time for equilibrium conditions to be established across the disk [15] [16] [17] [18]. Nishimura, Koseki, Fredlund, and Rahardjo introduced the micro porous membrane filter technique as an alternative to the

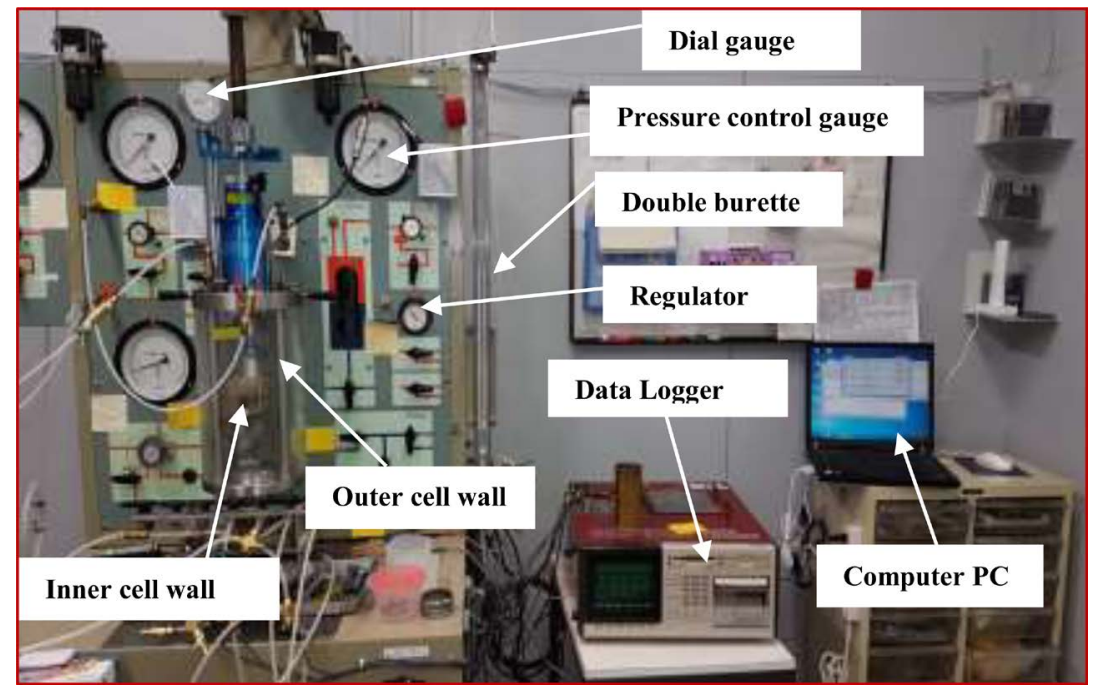

Figure 3. Modified triaxial test setup for SWCC measurements. 


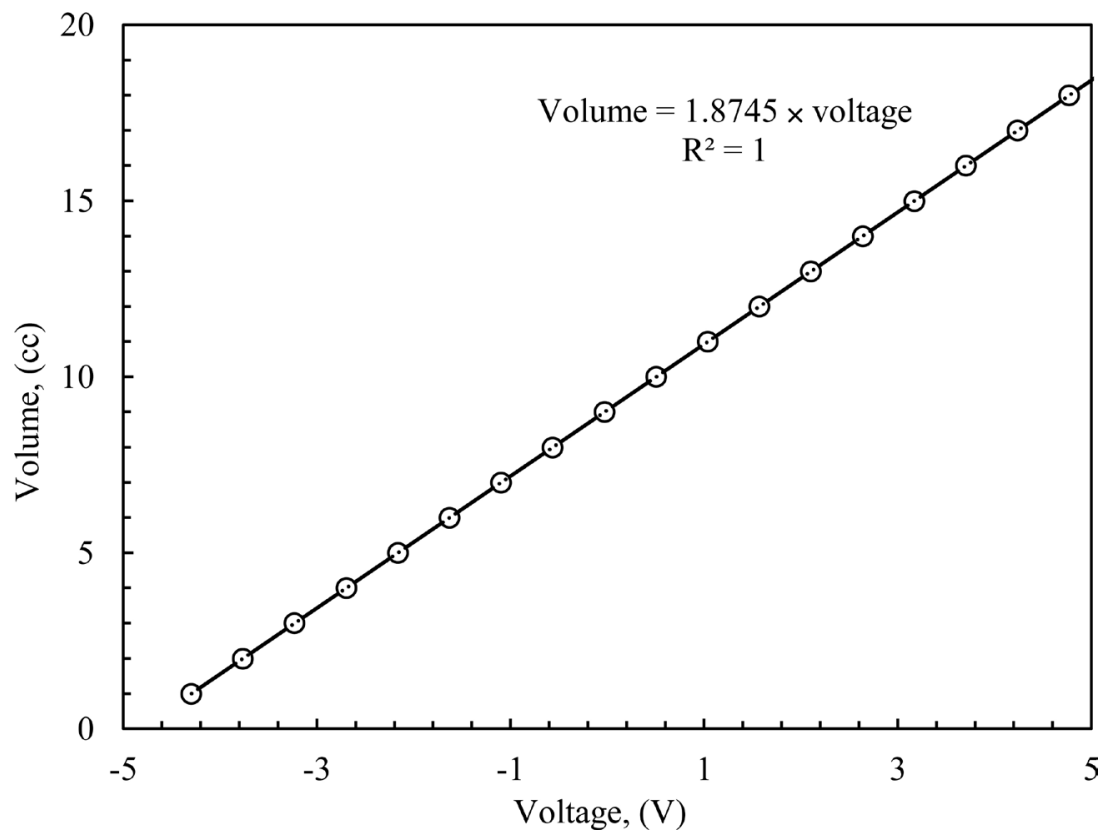

Figure 4. The relationship between voltage and volume of water in double glass burette.

ceramic disk for the measurement of soil-water characteristic curves. The membrane works on the same principle as the ceramic disk except that the amount of time required for establishing suction equilibrium is considerably reduced. The application of the membrane filter to the soil-water characteristic curve (SWCC tests) has shown that similar SWCCs can be obtained by employing the pressure plate apparatuses with either the ceramic disk or the membrane filter installed. In this research, SWCCs were conducted using the membrane filter technique by performing the tests under a maximum matric suction of $20 \mathrm{kPa}$. The pedestal was fixed with a membrane filter with an air entry value of $250 \mathrm{kPa}$. The maximum matric suction of $20 \mathrm{kPa}$ was essentially applied to the membrane filter pedestal to avoid air diffusion during the SWCC tests and keeping in mind the objective of the research. Further details on the properties of the membrane filter are outlined in the recent publication by Wang, Koseki, Nishimura, and Miyashita [19]. An initial vertical and confining stress of $50 \mathrm{kPa}$ was applied to the soil specimens under both stress conditions. As mentioned earlier, cell pressure, pore-air, and pore-water pressures were regulated separately. The net confining pressure or stress magnitude applied to the soil specimen remained constant throughout each test duration while establishing the desired matric suctions. Prior to commencement of the SWCC test, the soil specimens were first saturated through seepage from the bottom and this, in essence, released the initial matric suction of the specimens to zero. Drying and wetting paths of SWCC were established by gradually increasing and decreasing matric suction. Essentially air pressure in the chamber was regulated in order to establish the desired matric suctions. Consequently, to obtain the drying path of the SWCC, matric suctions were progressively increased from zero to $20 \mathrm{kPa}$. Subsequently, the wetting process was performed by following the path of decreasing matric suc- 
tion until the final applied matric suction was around zero. During the testing process, soil water moved in response to the externally applied suction and this accumulated in the double burette with elapsed time. The registered changes in the voltage on the differential pressure transducer of the modified triaxial apparatus were eventually translated into changes in the amount of water in the soil specimen. When the wetting process of the SWCC test was completed, the water content of the soil specimen was measured by oven-drying. The measured water content together with soil specimen changes in the amount of water recorded by the differential pressure transducer was used to back-calculate the water content corresponding to each applied suction value during drying and wetting process of the SWCC test. This testing procedure was repeated for each specified stress condition on all soil specimens in order to obtain the relationships between water content and matric suction described as SWCC for both drying and wetting paths until the target of the research was achieved.

\subsection{Isotropic Loading-Unloading Tests}

Several researchers have shown that application of suction changes the stress state of the soil. This change in stress state has a significant influence on the change in the void ratio of the soil [20]. Thus, it is vital to understand the influence of stress state on the compression index of the unsaturated silt soil. In this research, isotropic tests under both saturated and unsaturated conditions were conducted to investigate the compressibility behavior of the silt soil in addition to the SWCC tests conducted. Two soil specimens of the same initial void ratio were statically compacted and placed in the modified triaxial apparatus. The loading and unloading tests in unsaturated conditions were actually performed under a constant water content of $17.0 \%$ while apparent saturation through seepage to the bottom of the specimen was applied for saturated conditions. Figure 5 depicts typical compression curves (e-log $\sigma$ ) obtained for the silt soil specimen in both saturated and unsaturated conditions. The evaluated Compression Index $\left(C_{c}\right)$ and Swelling Index $\left(C_{s}\right)$ from the plotted compression curves were 0.012 and 0.005 for unsaturated conditions and 0.011 and 0.006 for saturated conditions respectively. As can be seen from the two plots, the void ratio decreased due to the application of confining stress. Perhaps, the stress state has a remarkable influence on the compressibility of the silt soil. During the loading process, confining pressure was gradually increased which inhibited stress development causing deformation on the soil specimen. It should be noted that deformation of the specimen perhaps occurred due to elastic deformation, volume change and slippage in the soil. The compression curves (e-log $\sigma^{2}$ ) further reflect that void ratio decreases with the increase of effective stress during compression, whereas increases with the decrease of effective stress during unloading.

\subsection{Undrained Triaxial Tests}

In this research study, a series of triaxial compression tests under undrained 


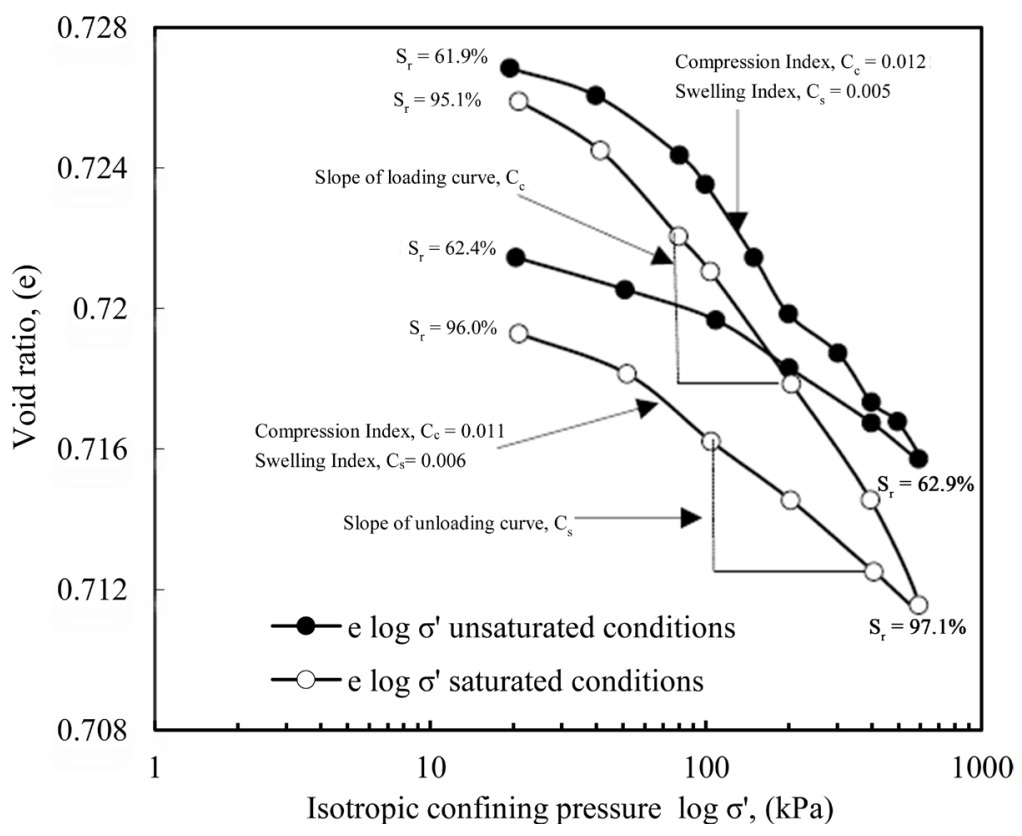

Figure 5. Compression curves (e-log $\sigma$ ) for both saturated and unsaturated conditions.

conditions were performed particularly to obtain a fundamental understanding of the effective stress strength properties ( $c^{\prime}$ and $\left.\Phi^{\prime}\right)$ of the silt soil. These properties are critical to stability related problems in the geotechnical engineering practice. This section provides a brief description of the procedure used to test the specimens and provides an analysis of the obtained results. Silt soil specimens of diameter $50 \mathrm{~mm}$ and height $100 \mathrm{~mm}$ were prepared through static compaction using a steel mold and placed on the modified triaxial apparatus. Apparent saturation through seepage to the bottom of the specimens was then applied for each specimen. The duration of saturation for the specimens depended so much on how dense the specimens were and the confining stress applied. Usually, all specimens tested at high confining stress took a long time to attain apparent saturation. Shearing of the soil specimens at a strain rate of $0.013 \%$ per minute with varying confining pressures were then performed. The shearing was immediately terminated when the axial strain was about $20 \%$.

During the shearing tests, pore water pressure was being generated according to the amount of confinement pressure applied. The data sets for the pore-water pressure phenomena are as shown in Figure 6 while the obtained stress-strain curves and effective mean stress paths of the saturated specimens are indicated in Figure 7 and Figure 8, respectively.

The stress-strain curves demonstrate typical behavior for saturated soil under triaxial testing. It can be seen that the deviator stresses increased with strain at different confining pressure conditions [21]. Each specimen reached residual conditions at which the deviator stresses became constant. Figure 7 also shows that, when confining pressure was increased, the soil stiffness, peak strength, and brittleness also increased. Therefore, a considerable increase in confinement pressure inhibited a large amount of shear in each soil specimen. 


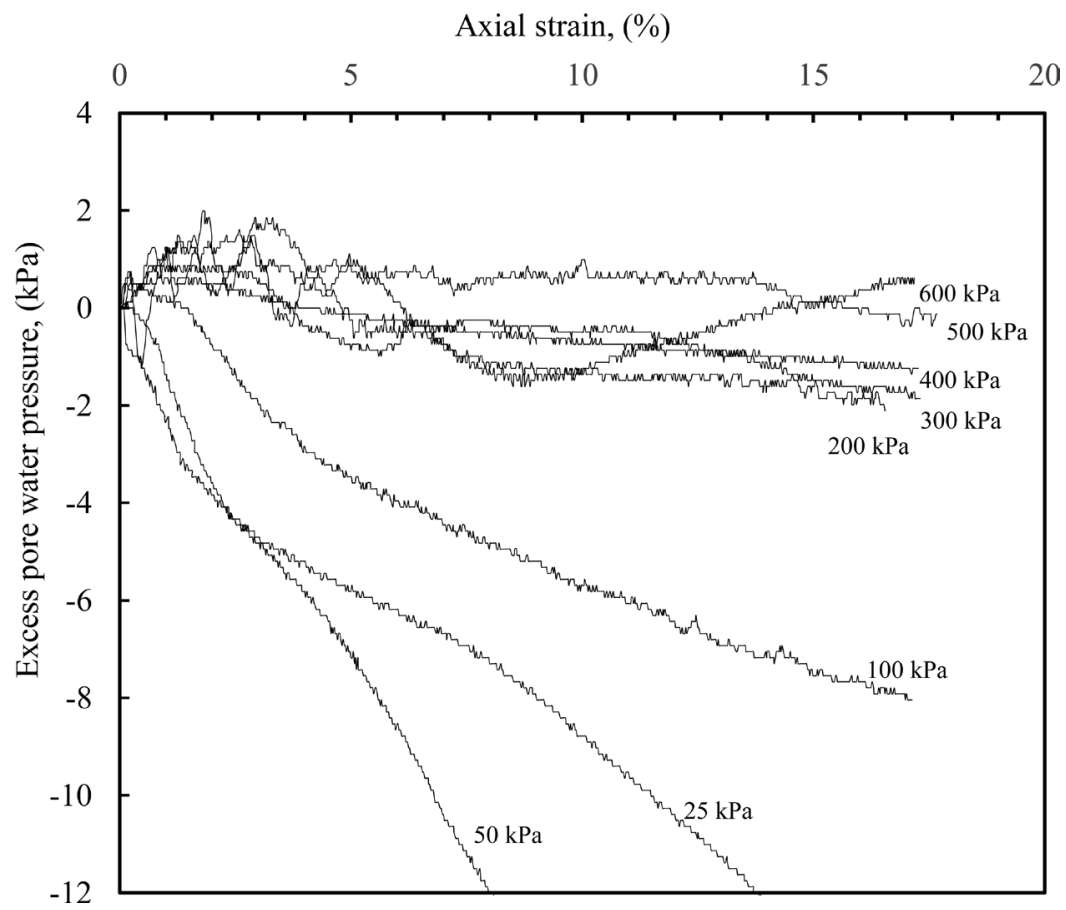

Figure 6. Excess pore-water pressure generation for unsaturated silt soil.

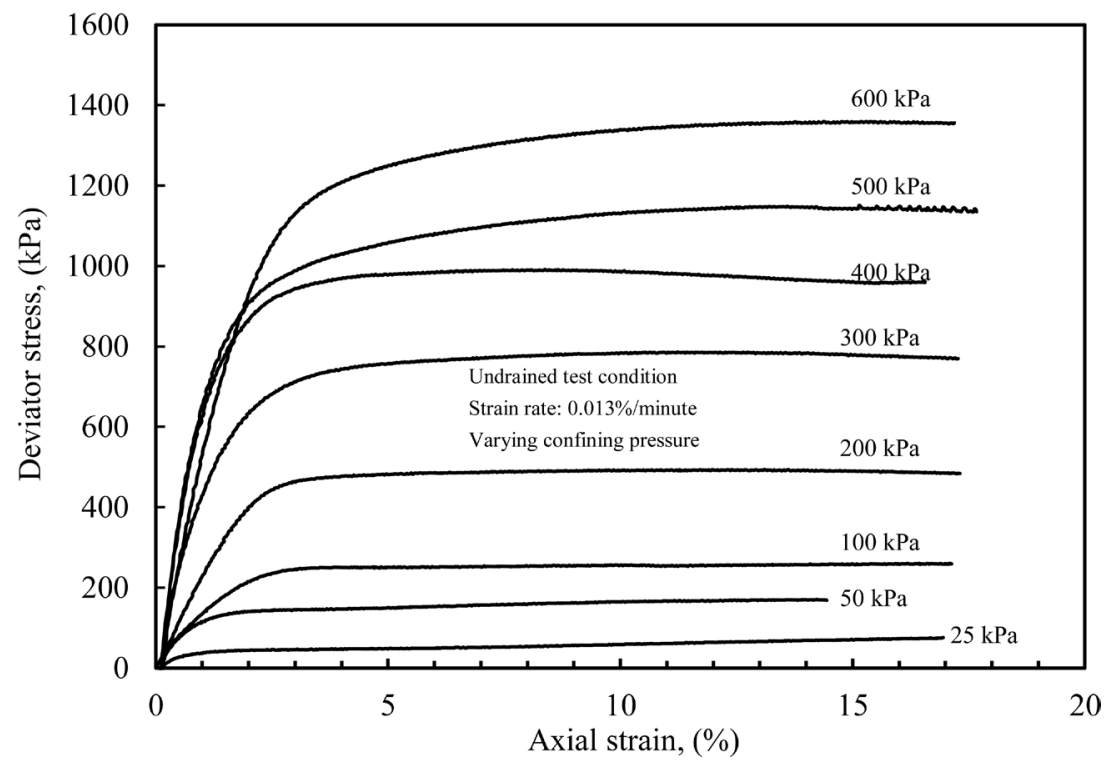

Figure 7. Stress-strain curves at different confining pressures.

All the eight specimens failed by bulging, without any distinct shear planes. The angle of internal friction was evaluated from the tangent of the failure envelope of the silt soil as shown in Figure 8. The calculated angle of internal friction was 33.40 degrees and cohesion was zero at peak failure and critical state conditions and the slopes of the critical state lines, $\mathrm{M}=1.3$, respectively. Overall, the experimental results obtained for triaxial tests show that the deviator stress and effective mean stress of the specimens significantly increase according to the increase in confining pressure. 


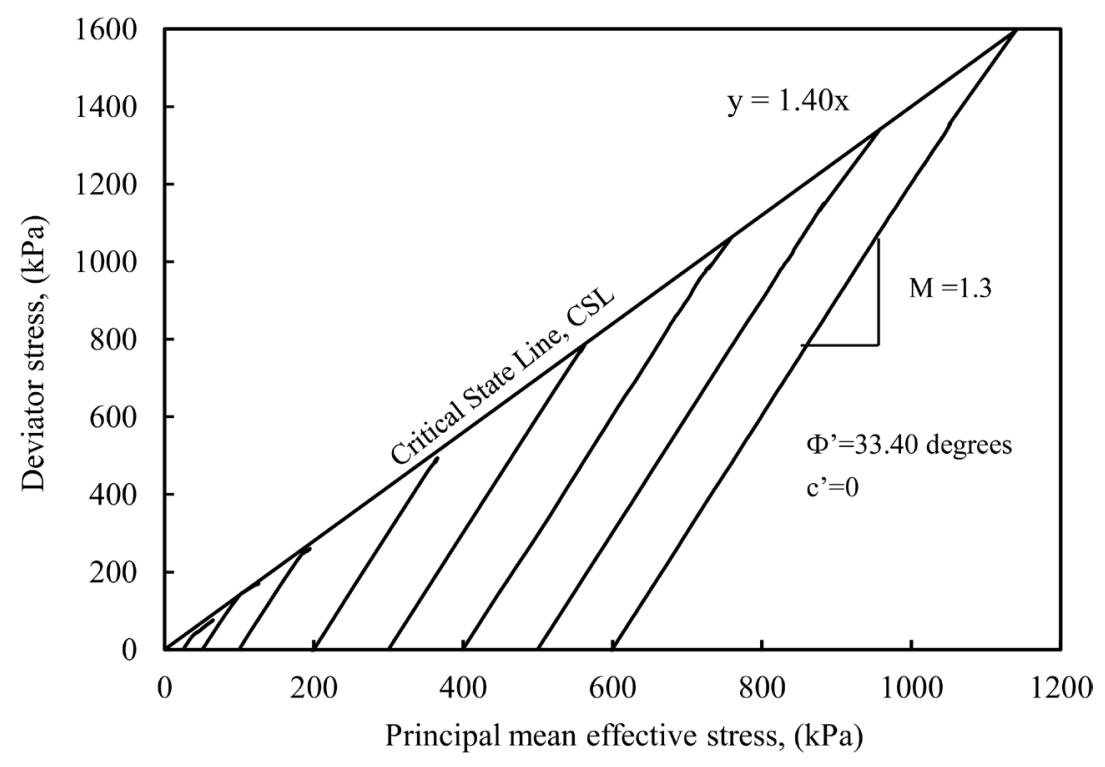

Figure 8. Effective mean stress path curves.

\section{Results and Discussions}

The experimental data describing the soil water characteristic curves in low suction ranges and under net confining stresses of $50 \mathrm{kPa}, 150 \mathrm{kPa}$, and $450 \mathrm{kPa}$ are presented in Figures 9-11, respectively. The data points in the figures basically represent the increments of matric suction with corresponding measurements of water content, the degree of saturation and the void ratio of the soil specimens. The results obtained may indicate that the influence of stress conditions have an effect on the shape of soil water characteristic curves.

The relationship between suction and water content of the specimens as shown in Figure 9 shows that the water content obtained under varying isotropic stress conditions decreased with increase in net confining pressure. This was observed when matric suction was less than $6 \mathrm{kPa}$ in the drying process. Thereafter, the water content attained equilibrium conditions for all isotropic stress conditions at which there was no significant change in water content as suction increased. This unique relationship was apparently observed to be almost identical for all the soil water characteristic curves conducted under these stress conditions. It seems that this variation in water content could be related to the micro and macro structure of the soil specimen. When the suction is greater than $6 \mathrm{kPa}$, the quantity of free water existing inside the inter-aggregate pores of the soil specimen is reduced. This change in the water volume could be related to the variation of the water content in the inter-aggregate (i.e. pores between particle aggregates) and intra-aggregate pores (i.e. pores inside aggregates) of the soil specimen. Delage and Lefebvre in their research indicated that the size of the inter-aggregate pores is larger than that of the intra-aggregate pores. This, therefore, may imply that from 0 - $6 \mathrm{kPa}$ suction application, pore water was initially drained from the inter-aggregate pores of the silt soil until equilibrium conditions were attained. On the other hand, matric suction between $6-20 \mathrm{kPa}$ 


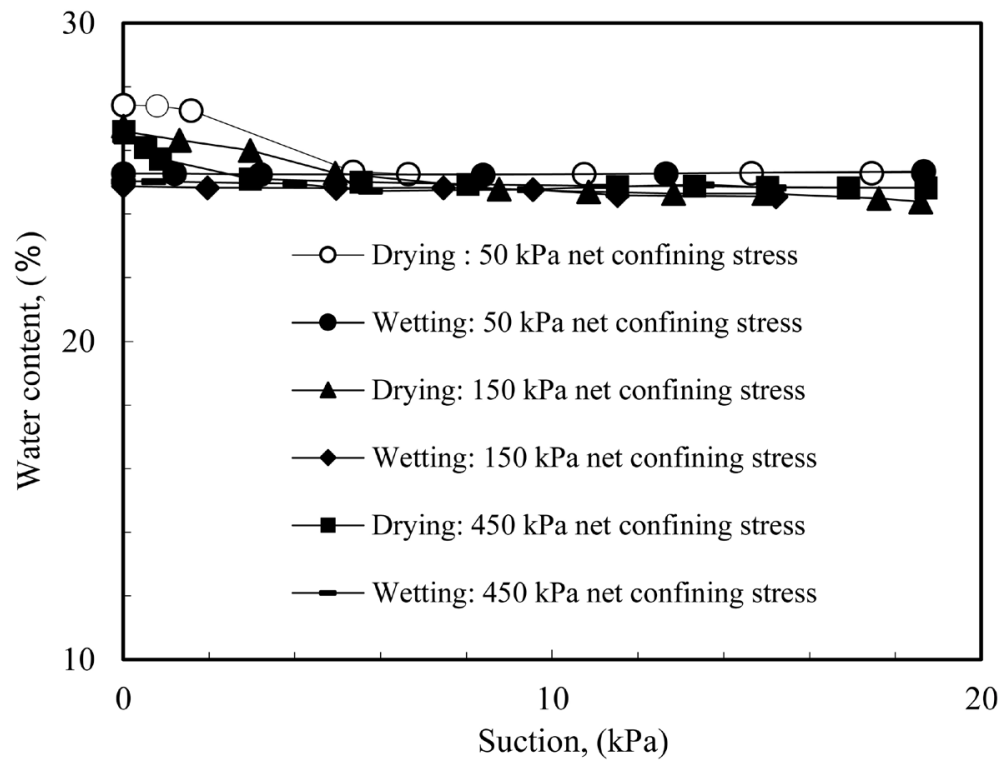

Figure 9. Suction vs. water content of silt soil with different magnitudes of net confining stresses.

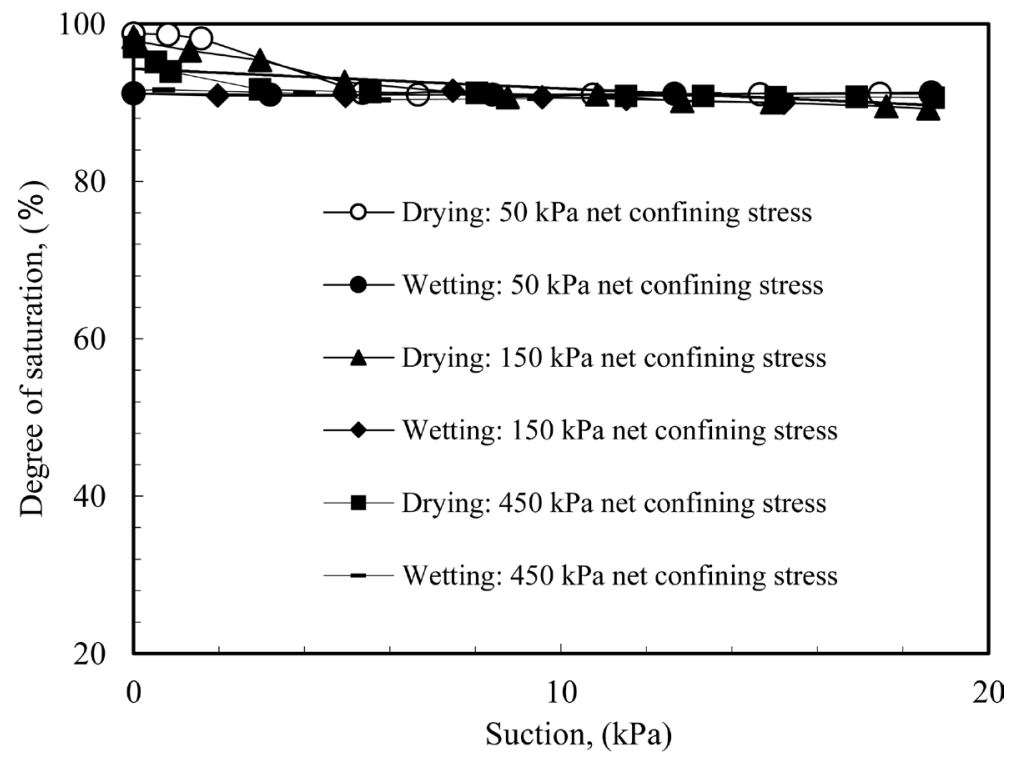

Figure 10. Suction vs. degree of saturation of silt soil with different magnitudes of net confining stresses.

was required to free water from the intra-aggregate pores of the silt soil although the change in water content was minimal as evidenced in Figure 9.

The SWCCs further shows that the water content decreased with increasing net confining stress and this was more evident when suction was less than $6 \mathrm{kPa}$. The drying and wetting branches of SWCC further showed less hysteresis when suction was less than $6 \mathrm{kPa}$ and thereafter no hysteresis was observed. The relationship between matric suction application and degree of saturation is as shown in Figure 10. There was certainly an increase in the degree of saturation as matric suction was applied during the drying process. The SWCCs obtained behaved 


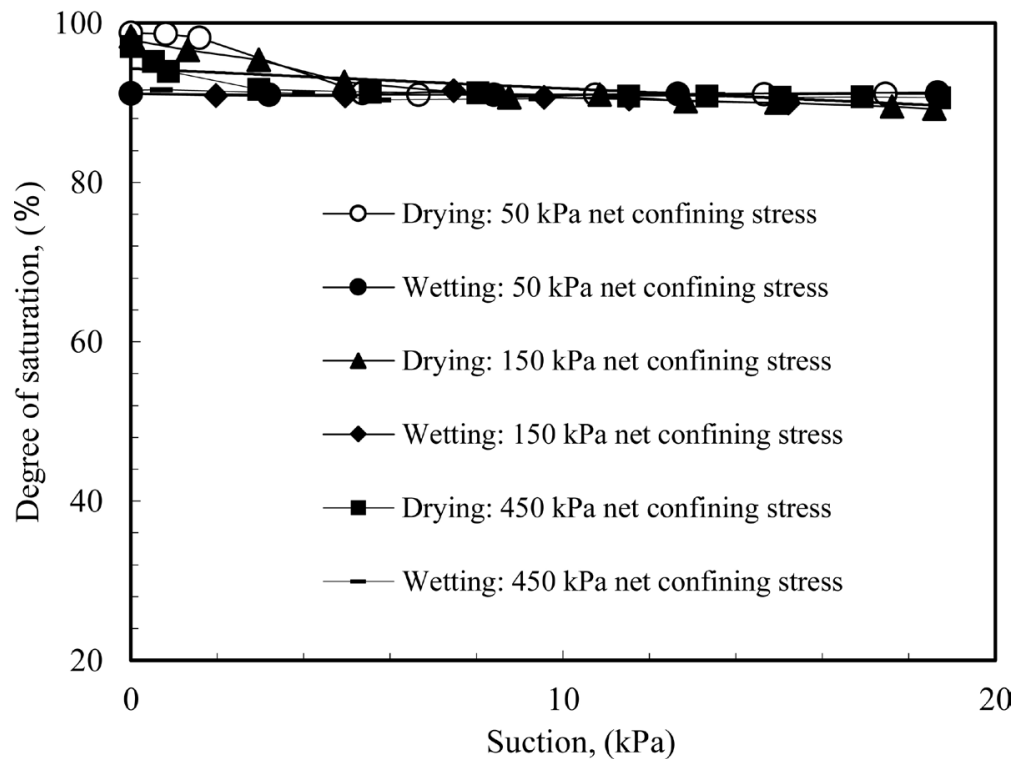

Figure 11. Suction vs. void ratio of silt soil with different magnitudes of net confining stresses.

almost identical as evidenced by the similar shape of each curve under different stress conditions. This could be related to the fact that the change in the void ratio of the specimen as evidenced in Figure 5 was practically negligible. However, this small change in the void ratio may have an effect on the degree of saturation of the specimens. For instance, in Figure 11, a small decrease in void ratio was observed when net confining pressure was increased for all specimens in both drying and wetting paths. Although this change in void ratio was almost negligible, it was observed to have an effect on the degree of saturation of the specimens. With the increase in net confining pressure, small changes in void ratio were noticed which essentially induced changes in the degree of saturation of the specimens. Since most of the testing was conducted under isotropic stress conditions, it is supposed that all soil specimens experienced equal deformations in all directions when subjected to an equal all around isotropic pressure. Therefore, the increase in the degree of saturation recorded for the specimens as can be seen in Figure 10 seem to have been induced by lateral pressure and changes in void ratio. Lateral pressure on isotropic compression condition is probably larger than that on one-dimensional condition. This may also have induced high retention activities in the soil specimens and consequently a reduction in the hydraulic conductivity. As net confining pressure was increased, isotropic compression may have caused the specimens to become dense in void structure and thereby decreasing soil moisture flow movement.

\section{Prediction of Model Parameters}

Several researchers have proposed various forms of mathematically defined SWCC models to characterize the soil water characteristic curve. In this context, the van Genuchten (1980) and the Fredlund and Xing (1994) models probably 
remain the most common mathematical concept among researchers and practicing engineers which have been widely adopted in both geotechnical and agricultural related fields [22]. In this research, an attempt was made to derive the parameters of the soil water characteristic curves obtained under different stress conditions using the two mentioned mathematical models. Firstly, the adopted model equations are reviewed in Table 2 as follows.

In order to predict the curve fitting parameters of the above models, the SWCCs measured under 50,150 and $450 \mathrm{kPa}$ stress conditions in the drying paths are reproduced and presented in Figure 12 for demonstration purposes. To obtain a closer fit to the experimental data, the fitting parameters $a, n$ and $m$ were determined using the nonlinear least-square analysis tool called Solver provided in Microsoft Excel add-in program. This tab in Excel enables estimation of fitting parameters provided the baseline data such as volumetric water content or degree of saturation and matric suction are available. The idea was to determine the model parameters such that the mathematical function or model passes as close as possible to the experimental data points without necessarily going

Table 2. Empirical models of SWCC.

\begin{tabular}{cc}
\hline Model name & Mathematical equation \\
\hline van Genuchten (1980) & $S_{r}=\frac{1}{\left(1+(a \psi)^{n}\right)^{m}}$ \\
Fredlund and Xing (1994) & $S_{r}=\frac{1}{\left(\operatorname{In}\left(\mathrm{e}+\left(\frac{\psi}{a}\right)^{n}\right)\right)^{m}}$ \\
\hline
\end{tabular}

Note. Where $S_{r}$ is the degree of saturation, $\psi$ is the soil suction, $a$ is the curve fitting parameter related to the air-entry value of the soil, $n$ is the curve fitting parameter related to the pore size distribution of the soil and the $m$ parameter is related to the asymmetry of the model.

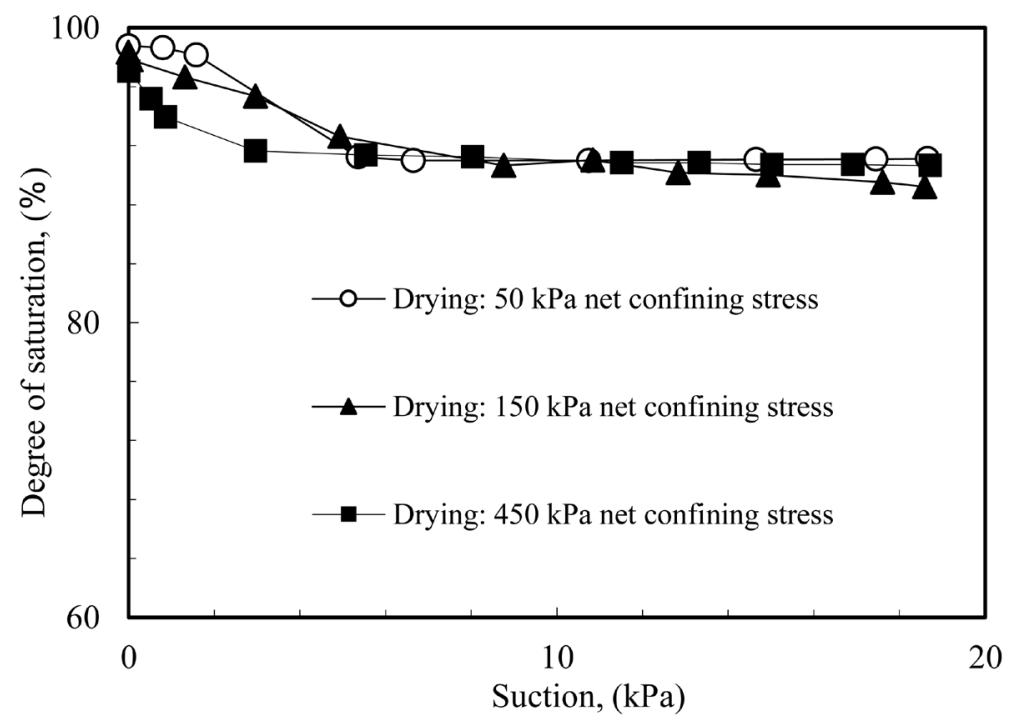

Figure 12. Suction vs. degree of saturation of silt soil with different magnitudes of net confining stresses in the drying portion. 
through any of the points. In order to achieve this objective, the sum of the squared deviations of the experimental data sets from the calculated data using the suggested model equations was minimized with respect to the three parameters $a, n$ and $m$. In this regard, the solver tab target was optimized to give the minimum root mean square error (RMSE) and the maximum correlation coefficient $\left(\mathrm{R}^{2}\right)$ for the data. The RMSE is basically a measure of the overall error of the evaluated mathematical model, with an obtained value closer to zero symbolizing a good fit for the data. The $\mathrm{R}^{2}$, on the other hand, is an indicator of the quality of fit. It is a measure of the correspondence between the experimental and the mathematical model data. Therefore, an $\mathrm{R}^{2}$ with a value closer to 1 simply indicates that the experimental and fitted data sets are as good as the shape of the mathematical model.

The values of the RMSE and $R^{2}$ were computed using the following expressions;

$$
\mathrm{RMSE}=\sqrt{\left(\frac{1}{K}\right)(\mathrm{SEE})}
$$

where SEE is the least-squares error of the fit and was defined as follows,

$$
\mathrm{SEE}=\sum_{i=1}^{K}\left[S_{r_{i}}^{e x p}-S_{r_{i}}^{f i t}\right]^{2}
$$

and $i=1,2, \cdots, k ; k$ is the number of soil water characteristic curve data sets for the silt soil, $S_{r}$ is the degree of saturation corresponding to the $i$ data pair for the soil and exp and fit denote the experimental and fitted values of the model.

Following the above procedure, silt soil fitting parameters required for modeling both the van Genuchten (1980) and the Fredlund and Xing (1994) models were determined and these are presented in Table 3. On the other hand, Figure 13 shows the best-fit curve of the soil water characteristic curve to the experimental data obtained for the silt soil under different stress conditions. The figure clearly shows that all the mathematical models gave relatively realistic fits with the experimental data sets. The difference between the experimental data and fitted SWCCs exhibited considerably minimal deviations. Both fitted curve models produced almost identical curves and showed much closeness to each other. Therefore, the obtained results seem to indicate that both models can perform better in terms of the best for fit for this particular silt soil. On the other hand,

Table 3. Model parameter values for silt soil.

\begin{tabular}{ccccccc}
\hline & \multicolumn{3}{c}{ Model parameters } & \multirow{2}{*}{ RMSE } & $R^{2}$ \\
\cline { 2 - 5 } Mathematical model name & $a$ & $n$ & $m$ & & \\
\hline van Genuchten (1980) & 0.00 & 0.38 & 1.32 & 0.65 & 0.99 \\
Fredlund and Xing (1994) & 2.47 & 0.55 & 0.08 & 0.69 & 0.99 \\
\hline
\end{tabular}

Note. $a, n$ and $m$ are model fitting parameters of the soil water characteristic curve for unsaturated silt soil. RMSE is the root mean squared error or a measure of how well the two models performed with experimental data and $\mathrm{R}^{2}$ is the correlation coefficient or a relative measure of fit between the experimental and model data sets. 


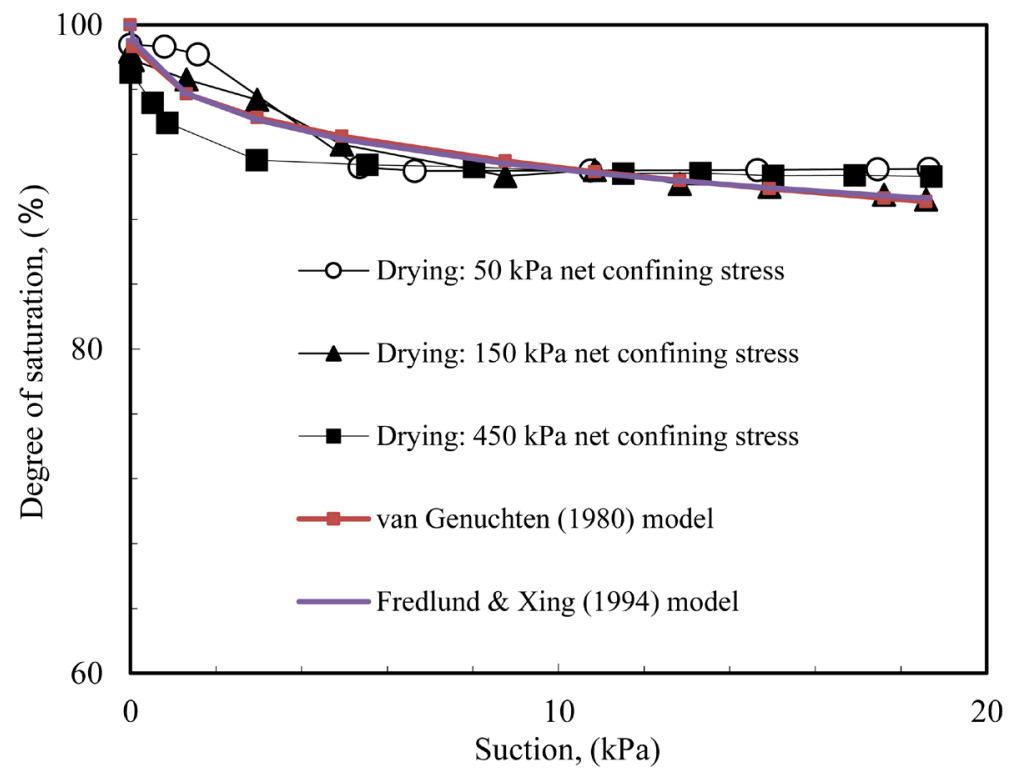

Figure 13. Best-fit curves to experimental data of silt soil using van Genuchten (1980) and Fredlund and Xing (1994) models.

the RMSE values shown in Table 3 clearly show that the models are closely associated with the experimental data. The fitting errors for both models are smaller and therefore most suitable in describing the experimental data for the SWCC of this particular silt soil.

More so, the obtained values of the $R^{2}(0.99)$ for both models clearly indicate that the fitted values and the experimental data sets are nearly located around the line of perfect agreement.

\section{Conclusions}

This study utilized the microporous membrane filter technique for the measurement of Soil Water Characteristic Curves (SWCCs) in low suction ranges and under different stress conditions for an unsaturated silt soil. The SWCCs were measured under one-dimensional and isotropic stress conditions with stresses of 50,150 and $450 \mathrm{kPa}$, respectively. An attempt was made to curve fit the experimental data with two most widely accepted models in the geotechnical engineering practice. The summary of conclusions which are drawn from this study includes;

1) Different stress conditions have an effect on the shape of SWCCs in low matric suction ranges. Lateral pressure on isotropic compression causes the specimens to become dense in void structure thereby causing high retention activities and a decrease in soil moisture flow movement in the soil specimens.

2) The SWCCs revealed that an increase in the net confining pressure decreased the void ratio and consequently increased the degree of saturation of the soil specimens. Thus, different stress conditions have an effect on measured SWCCs.

3) There were considerably minimal deviations in the correspondence be- 
tween the measured SWCCs under low suction ranges and different stress conditions and the fitted SWCCs. Both mathematical models of the van Genuchten (1980) and the Fredlund and Xing (1994) gave relatively realistic fits with the experimental data though they required further modifications to take into full account the effect of different stress conditions.

One of the limitations to this study is the state of stress considered in the experimental work (i.e., one-dimensional and isotropic stress conditions) for the soil specimens. In nature, most soils are anisotropic due to the modes of deposition or as a result of subsequent changes caused by various stresses acting on them [23]. However, the anisotropic phase of triaxial tests is not only time consuming but expensive as well. These tests require special testing equipment. The testing conducted in the present study was sufficient to approach the target of this research.

\section{Acknowledgements}

This research did not receive any special funding other than the support of Japan International Cooperation (JICA) through the ABE Initiative scholarship offered to the first author. The authors are indebted to the management of the Department of Civil Engineering at Ashikaga University for providing the necessary laboratory materials and apparatus utilized in the experimental part of this research.

\section{Conflicts of Interest}

The authors declare no conflicts of interest regarding the publication of this paper.

\section{References}

[1] Fredlund, D.G. and Xing, A.Q. (1994) Equations for the Soil Water Characteristic Curve. Canadian Geotechnical Journal, 31, 521-532. https://doi.org/10.1139/t94-061

[2] Ng, C.W.W. and Pang, Y.W. (2000) Influence of Stress State on Soil-Water Characteristics and Slope Stability. Journal of Geotechnical and Geoenvironmental Engineering, 126, 157-166. https://doi.org/10.1061/(ASCE)1090-0241(2000)126:2(157)

[3] Tavakoli, D.M.H., Habibagahi, G. and Nikooee, E. (2014) Effect of Confining Stress on Soil-Water Retention Curve and Its Impact on the Shear Strength of Unsaturated Soils. Vadose Zone Journal, 13, 1-11.

[4] Li, B. and Chen, Y. (2016) Influence of Dry Density on Soil-Water Retention Curve of Unsaturated Soils and Its Mechanism Based on Mercury Intrusion Porosimetry. Transactions of Tianjin University, 22, 268-272. https://doi.org/10.1007/s12209-016-2744-5

[5] Nishimura, T., Hirabayashi, Y., Fredlund, D.G. and Gan, J.K.M. (1999) Influence of Stress History on the Strength Parameters of an Unsaturated Statically Compacted Soil. Canadian Geotechnical Journal, 36, 251-261. https://doi.org/10.1139/t98-098

[6] Zhou, J. and Yu, J. (2005) Influences Affecting the Soil-Water Characteristic Curve. Journal of Zhejiang University Science, 797-804. https://doi.org/10.1631/jzus.2005.A0797

[7] Vanapalli, S.K., Sillers, W.S. and Fredlund, M.D. (1999) The Meaning and Relev- 
ance of Residual Water Content to Unsaturated Soils. 51 st Canadian Geotechnical Conference, Edmonton, 4-7 October 1998, 101-108.

[8] Delage, P. and Lefebvre, G. (1984) Study of the Structure of a Sensitive Champlain Clay and of Its Evolution during Consolidation. Canadian Geotechnical Journal, 21, 21-23. https://doi.org/10.1139/t84-003

[9] Nishimura, T., Koseki, J., Fredlund, D.G. and Rahardjo, H. (2012) Microporous Membrane Technology for Measurement of the Soil-Water Characteristic Curve. Canadian Geotechnical Journal, 35, 201-208. Https://doi.org/10.1520/GTJ103670

[10] Habasimbi, P. and Nishimura, T. (2018) Comparison of Soil-Water Characteristic Curves in One-Dimensional and Isotropic Stress Conditions. MDPI Soil System Journal, 2, 43. https://doi.org/10.3390/soilsystems2030043

[11] Ishikawa, T., Tokoro, T., Ito, K. and Miura, S. (2010) Testing Methods for Hydro-Mechanical Characteristics of Unsaturated Soils Subjected to One-Dimensional Freeze-Thaw Action. Soils and Foundations, 50, 431-440. https://doi.org/10.3208/sandf.50.431

[12] Ishikawa, T., Zhang, Y., Tokoro, T. and Miura, S. (2014) Medium-Size Triaxial Apparatus for Unsaturated Granular Subbase Course Materials. Soils and Foundations, 54, 67-80.

[13] Uchimura, T., Gizachew, G., Wang, L., Nishie, S. and Seko, I. (2013) Deformation and Water Seepage Observed in a Natural Slope during Failure Process by Artificial Heavy Rainfall. Proc. 18 th International Conference on Soil Mech. Geotechnical Engineers, Paris, 2-6 September 2013, 2273-2274.

[14] JIS (2009) Test Method for Soil Compaction Using a Rammer. JIS Standard A1210. Japanese Industrial Standard Committee.

[15] Wang, H., Koseki, J., Sato, T., Chiaro, G. and Tan Tian, J. (2017) Effect of Saturation on Liquefaction Resistance of Iron Ore Fines and Sandy Soils. Soils and Foundations, 56, 732-744. https://doi.org/10.1016/j.sandf.2016.07.013

[16] Ridley, A.M. and Burland, J.B. (1993) A New Instrument for the Measurement of Soil Moisture Suction. Geotechnique, 43, 321-324. https://doi.org/10.1680/geot.1993.43.2.321

[17] Gee, G.W., Word, A.L., Zhang, Z.F., Campbell, G.S. and Mathison, J. (2002) The Influence of Hydraulic Non-Equilibrium on Pressure Plate Data. Vadose Zone Journal, 1, 172-178. https://doi.org/10.2136/vzj2002.1720

[18] Oliveira, O.M. and Fernando, F.A.M. (2006) Study of Equilibration Time in the Pressure Plate. ASCE Unsaturated Soils, Carefree, 2-6 April 2006, 1864-1874. https://doi.org/10.1061/40802(189)157

[19] Wang, H., Koseki, J., Nishimura, T. and Miyashita, Y. (2017) Membrane Filter Properties and Application of the Filter to Undrained Cyclic Triaxial Test of Unsaturated Materials. Canadian Geotechnical Journal, 54, 1196-1202. https://doi.org/10.1139/cgj-2016-0507

[20] Miller, G.A., Khoury, C.N., Muraleetharan, K.K., Liu, C. and Kibbey, T.C.G. (2008) Effects of Soil Skeleton Deformations on Hysteretic Soil Water Characteristic Curves: Experiments and Simulations. Water Resources Research, 44. https://doi.org/10.1029/2007WR006492

[21] Wang, Q., Pufahl, D.E. and Fredlund, D.G. (2002) A Study of Critical State on an Unsaturated Silty Soil. Canadian Geotechnical Journal, 39, 213-218. https://doi.org/10.1139/t01-086

[22] Matlan, S.J., Mukhlisin, M. and Taha, M.R. (2014) Performance Evaluation of 
Four-Parameter Models of the Soil-Water Characteristic Curve. Scientific World Journal, 2014, Article ID: 569851. https://doi.org/10.1155/2014/569851

[23] Kamei, T. (2003) Effects of Stress Paths on Undrained Shear Characteristics of Anisotropically Consolidated Cohesive Soil. Journal of the Japan Society of Engineering Geology, 44, 119-122. https://doi.org/10.5110/jjseg.44.119 